\title{
Evaluating retrofit options in a historical city center: Relevance of bio-based insulation and the need to consider complex urban form in decision-making
}

Sophie Claude ${ }^{1}$, Stéphane Ginestet ${ }^{1}$, Marion Bonhomme ${ }^{1}$, Gilles Escadeillas ${ }^{1}$, Jonathon Taylor ${ }^{2}$, Valentina Marincioni² ${ }^{2}$ Ivan Korolija ${ }^{2}$ and Hector Altamirano ${ }^{2}$

${ }^{1}$ Laboratory for Materials and Durability of Construction Works (LMDC), Department of Civil Engineering, Institut National des Sciences Appliquées de Toulouse, Toulouse, France, sclaude@insa-toulouse.fr;

${ }^{2}$ Bartlett School of Environment Energy and Resources, University College London, London, United Kingdom.

\section{Abstract}

Historical dwellings make up a significant fraction of the French building stock and require substantial retrofitting to reduce their energy consumption and improve their thermal comfort. In the city center of Cahors, France, the old medieval dwellings are considered as valuable cultural heritage and internal insulation is often the only insulation technique that can be used when the architectural value of the exterior façade is to be preserved. However, internal insulation may have an impact upon the hygrothermal performance of the wall, leading to lowered drying capacity, with possible interstitial condensation and mold growth. Hygrothermal models may be used to assess the risk of failure, but the accuracy of the results depends on how reliable the input data is, including external boundary conditions, which may vary significantly in dense medieval cities such as Cahors. In this study, a Geographical Information System model of Cahors is used to develop EnergyPlus models of individual dwellings. The boundary conditions output by these models are, in turn, used to model the hygrothermal performance of façades with different internal insulations, using the hygrothermal tool Delphin. The Delphin outputs are then analyzed with the VTT model, a mold growth assessment model. Results highlight a quantitative correlation between some urban morphology characteristics and the hygrothermal performance of refurbished walls, with some configurations raising the risk of damage patterns. We find that bio-based insulation presents a better hygrothermal performance than mineral wool in most of the configurations.

\section{Introduction}

Energy-efficient retrofitting of existing buildings is essential to reduce energy consumption and improve indoor comfort but retrofitting buildings in historical city centers can present specific challenges. In the center of Cahors, France, owners have to deal with urban heritage preservation rules, numerous local stakeholders, and condominium property agreements that sometimes slow the refurbishment process. Before modifying the thermal and hygrothermal behaviour of a building, retrofit options should consider the natural ventilation, the great sensitivity of old materials to humidity, their high thermal inertia and the influence of the urban micro-climate, which are specific to urban historical buildings [1,2]. The urban fabric of Cahors is particularly dense and contiguous with four main orientations of the façades, and the very narrow roads reduce the access of solar radiation. The main construction typologies are massive walls (bricks or stone) and timber framed walls. In order to preserve the architectural value of the exterior façade, internal insulation will be preferred in most of these buildings. However, insulating the façade from the inside will result in colder façades during winter and a reduced 
drying potential of the wall, which can lead to mold growth on the surface or in the interface between the interior insulation and wall. In this complex context, in order to promote appropriate and sustainable insulation techniques for historical buildings, the city council of Cahors set up the ENERPAT project. ENERPAT is the contraction of Energy and Patrimony, the medieval city center being considered as cultural heritage (Figure 1).
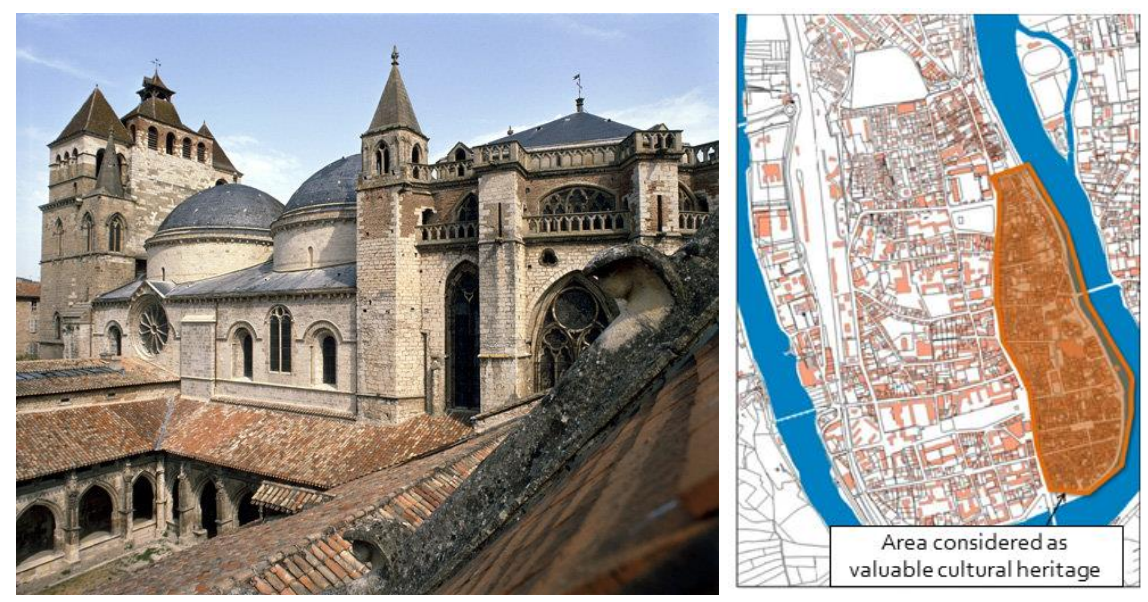

Figure 1 : City center of Cahors considered as cultural heritage

The project uses a multi-scaled experimental and numerical analysis and a Living Lab methodology as described in [3] and in Figure 2 to promote the use of a bio-based insulation. Key components of the Living Lab are real-life environment testing and co-creation, enabling local stakeholders such as craftsmen, architects or local politicians to work side-by-side with researchers to formulate technical solutions.

Here, only the numerical results will be presented. We focused on the two main particularities of urban historical dwellings: the specific urban morphology and the moisture sensitivity, to see how these two parameters influence the hygrothermal performance of the walls located in a very dense urban morphology. Taking account of these parameters allows us to evaluate indoor insulation systems more accurately according to the typology of the wall.

The goal is to provide easy-to-understand scientific information for planners and politicians. Principal components analysis has been used to identify key factors for moisture risk in order to develop a general guide with simplified indicators enabling planners to identify walls that may become vulnerable after thermal retrofit. 


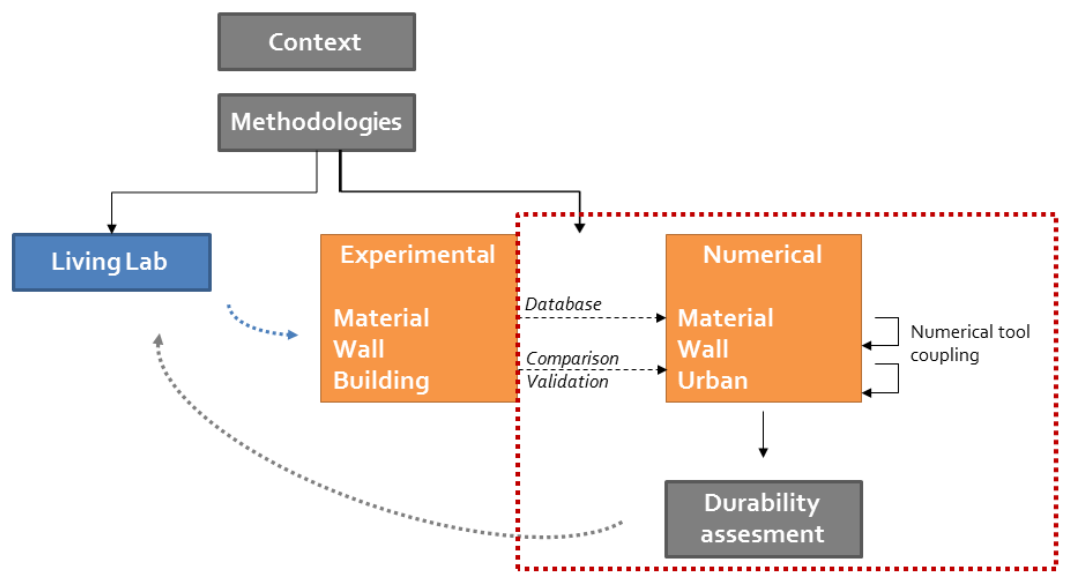

Figure 2 : Global methodology of the project

\section{Particularity of thermal refurbishment of medieval historical city center}

\subsection{Urban morphology}

Cities are complex structures and the urban form significantly influences a building's energy consumption [4] and the urban climate [5]. Density, aspect ratio, compactness, and street orientation of the urban fabric will modify the access to solar radiation of the exterior façades, the exterior surface area available for heat loss and protection from the dominant wind, among others [6]. Medieval city centers, like that of Cahors, are considered as a specifically dense urban form [7]. Urban morphological parameters are dominating factors for the formation of urban climate conditions [5]. The urban microclimate modifies the exterior boundary conditions (mainly solar radiation, convective heat transfer coefficient and wind pressure on the building, modifying the Wind Driven Rain (WDR) exposure) and so the hygrothermal performance of the wall. In urban configurations, wind velocity and pressure on buildings may not be easy to evaluate, and studies have sought to examine factors such as urban canyon wind velocity and direction [8]. Urban morphology modifies both long-wave and short-wave radiations, with highly sheltered façades receiving less solar radiation, more ground and building emission and less sky emission, thus avoiding night overcooling.

The urban microclimate can strongly affect boundary conditions [9]. The boundary conditions imposed on a mathematical model are often as critical to its accuracy as the proper modelling of the moisture physics. But in practice, detailed building energy simulations (BES) still typically rely on stand-alone building configurations, not accounting for the influence of neighboring buildings, except perhaps for shading. Here, we seek to account for local modifications of radiations in urban environment.

\subsection{Risks of excess moisture}

Various studies have pointed out the risk of a moisture degradation after an internal insulation [10], [11]. Furthermore, for historical buildings, their high moisture sensitivity makes a moisture assessment study essential prior to a retrofit.

Building insulation is commonly achieved using materials obtained from petrochemicals (mainly polystyrene) or from sources requiring high energy consumptions for their processing (glass and rock wools) [12]. Bio-based insulation offers an alternative choice with low carbon footprint [13], [14], using materials that are often recyclable, and for plant-based ones able to sequester 
atmospheric carbon during the lifetime of the plant. Recyclability of insulation materials will mainly depend on the chosen binding agent, for example the additions of polymer fibers into wood fiber panels will make more complex the recycling phase. Bio-based materials also present specific hygrothermal properties that might be better suited to the hygrothermal behavior of historical buildings: unlike oil- and chemical-based insulation materials, they are permeable and capable of buffering moisture [15]. In the present study, we worked with a mix of hemp and lime handmade by a local craftsman.

To assess the hygrothermal performance of a wall and to reduce risks of pathology, it is essential to use a relevant pathology indicator. Viitanen et al. [16] point to biodeterioration as an important critical factor for analyzing pathology risks and usage of different materials. Mold and decay damage in buildings are caused by moisture exceeding the tolerance of structures.

In several classifications [17], [18], mineral materials or oil based insulations are considered as less sensitive to mold growth than natural materials. Various studies [19], [20] have focused on the risk of bio-deterioration in bio-based materials. Sedlbauer et al. [21] show that the hemp used in this study is less sensitive to mold growth than other bio-based materials, such as straw or cellulose. Furthermore, lime generates an alkaline environment (pH about 12.5), which inhibits the apparition of mold during the first months.

\section{Materials and method}

\subsection{Coupling various numerical tools}

A reliable moisture and mold risk assessment for historical buildings is possible only taking into account the specificities of a thermal refurbishment of a medieval city center, particularly the urban morphology and the moisture sensitivity of the construction materials. Furthermore, the high hygroscopicity of bio-based materials requires detailed hygrothermal modelling. Here, we link various tools enabling us to obtain accurate external boundary conditions to run the hygrothermal model using geographical data. For this purpose, a modelling framework is employed that calculates external façade moisture and temperature levels using the hygrothermal model Delphin 5.8, with boundary conditions modelled from EnergyPlus files generated using geographical data from ArcGIS (see Figure 3).

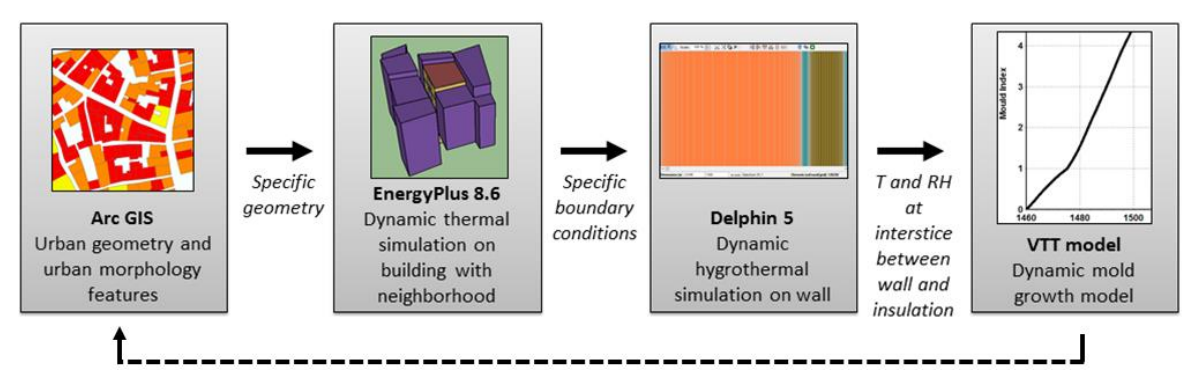

Figure 3: Coupling numerical tools for risk of pathology assessment

Individual building geometry and the geometry and locations of neighboring buildings are exported from a GIS database with building footprint and height data using ArcGIS. The reference data are provided by the French National Geographical Institute (C) IGN - 2015 - BD TOPO). The same data is then used to model the building envelopes in the modelling tool EnergyPlus, which allows whole-building modelling of each building and its neighbors with the 
relevant geometry. All the façades of each floor of the buildings of a representative city block have been modelled, i.e., more than 800 walls (which represents around $10000 \mathrm{~m}^{2}$ ).

Here, EnergyPlus is used to obtain specific external boundary conditions, such as the surface temperature of the external fabric elements. We consider that all outdoor thermal influences are lumped together to give an equivalent outdoor surface temperature [22], which combines air temperature, convection, and also solar and longwave radiation, which will vary depending on the shading of buildings. Each building is divided into $2.7 \mathrm{~m}$ high stories and the mean exterior surface temperature of each story is taken.

Following the EnergyPlus simulations, surface temperature is implemented in Delphin hygrothermal simulations as exterior boundary conditions; Delphin is used here, rather than the Heat and Moisture Transport (HAMT) tool in EnergyPlus, because of its ability to model winddriven rain, and its better discretization of the fabric elements. Among the climatic hazards having most influence on historical buildings, wind-driven rain (WDR) is found to be especially detrimental as it may cause surface erosion and facilitate moisture penetration and biodeterioration [23], [24]. Furthermore, the high water absorption coefficient of ancient bricks may lead to a greater risk of moisture from the rain reaching the warm side of the masonry. Finally, the temperature and relative humidity at the interface between the masonry and the insulation obtained from Delphin are treated with the VTT model to define the risk of mold growth.

\subsection{Configurations and parameter variations studied}

In order to obtain a broad view of the critical parameters and the influence of urban form, we model all the individual buildings of the city center and all their façades, exterior boundary conditions being different for each story of each façade according to the orientation and the neighboring buildings.

The numerical study focuses on two different historical fabrics, representative of the historical center of Cahors: a timber-framed wall infilled with bricks and a massive brick wall. For both fabrics, we study the hygrothermal performance of two different insulation systems: a conventional insulation (mineral wool) and a bio-based insulation (hemp and lime mix). The details of the configurations are presented in Figure 4.
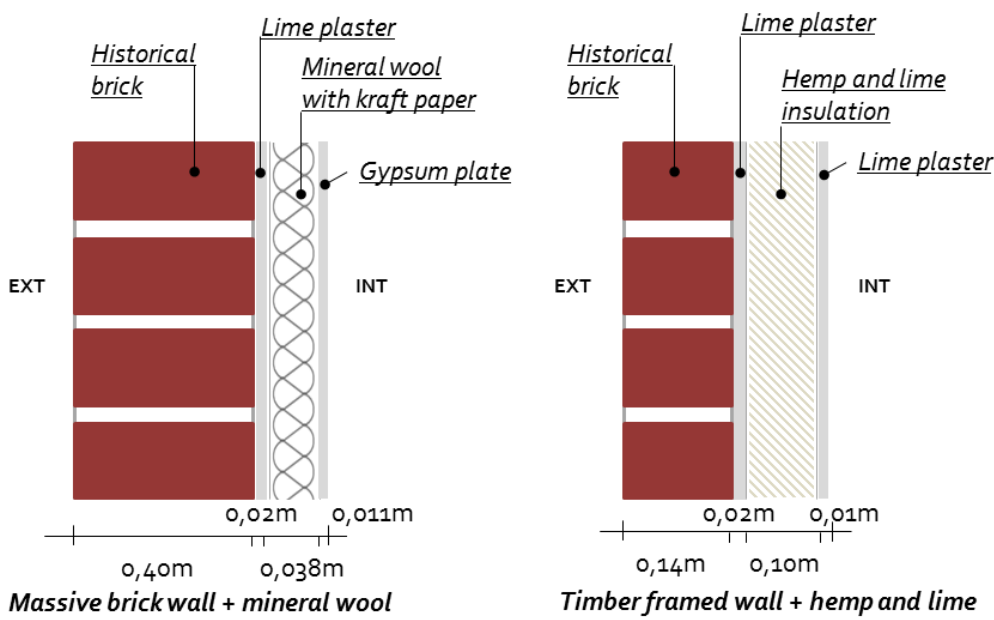

Figure 4: Two of the four configurations studied 
Both insulation systems have the same thermal transmittance. Hygric and thermal properties of bio-based insulation and historical bricks were characterized in order to compensate for the lack of data on these materials (Table 1).

Table 1: Hygric and thermal properties of materials used in DELPHIN 5

Source Lab characterization DELPHIN 5 database

\begin{tabular}{|c|c|c|c|c|c|}
\hline Materials & $\begin{array}{c}16^{\text {th }} \\
\text { century } \\
\text { brick }\end{array}$ & $\begin{array}{l}\text { Hemp and } \\
\text { lime }\end{array}$ & $\begin{array}{l}\text { Mineral wool/Kraft } \\
\text { paper }\end{array}$ & $\begin{array}{l}\text { Gypsum } \\
\text { plate }\end{array}$ & Lime plaster \\
\hline Density $(\mathrm{kg} / \mathrm{m} 3)$ & 1616 & 440 & $37 / 120$ & 850 & 1650 \\
\hline $\begin{array}{l}\text { Dry thermal } \\
\text { conductivity } \\
(W /(\text { K.m) })\end{array}$ & 0.49 & 0.107 & $0.04 / 0.42$ & 0.20 & 0.67 \\
\hline $\begin{array}{l}\text { Thermal capacity } \\
(\mathrm{J} /(\mathrm{kg} . \mathrm{K}))\end{array}$ & 800 & 1000 & $840 / 1500$ & 850 & 840 \\
\hline $\begin{array}{l}\text { Vapour resistance } \\
\text { coefficient (-) }\end{array}$ & 9 & 6.5 & $1 / 3000$ & 10 & 8.9 \\
\hline $\begin{array}{l}\text { Water absorption } \\
\text { coefficient } \\
\left(\mathrm{kg} \cdot \mathrm{m}^{-2} \cdot \mathrm{s}^{-0.5}\right)\end{array}$ & 0.28 & 0.196 & $0 / 1.10^{-5}$ & 0.27 & 0.22 \\
\hline
\end{tabular}

The dependence between relative humidity and thermal conductivity has been measured for hemp and lime mix with a hot wire method (Figure 5) and a specific function of moisture depending thermal conductivity was created in Delphin 5.

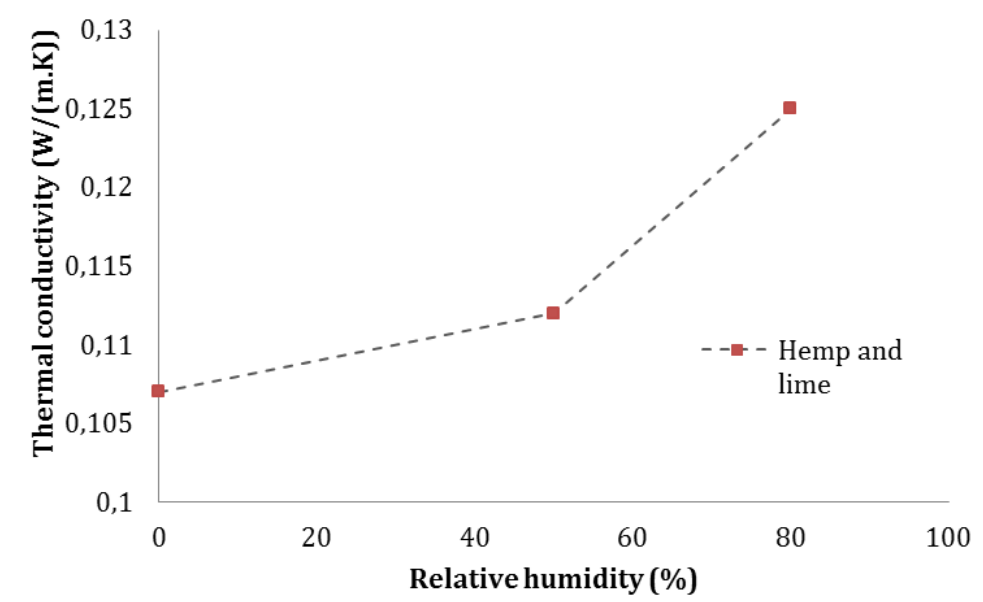

Figure 5 : Hemp and lime mix thermal conductivity related to relative humidity

The climate conditions at the interior side of the wall are applied according to modelling standard EN13788 (ISO13788, 2012) for relative humidity and air temperature, with a continental climate and high occupancy.

The exterior climatic data used in EnergyPlus was generated by the Meteonorm program for Cahors.

\subsection{Assessment of moisture safety}


The moisture safety assessment is based on the risk of mold growth between the existing wall and the interior insulation. Various mold growth estimation methods have been developed in recent years but, according to Vereecken and Roels [25], the VTT model, using a dynamic approach, is one of the most relevant. The model takes account of the material's sensitivity to mold growth (material group and surface quality), the $\mathrm{RH}$, and the temperature conditions.

The risk of mold growth in the VTT model is presented as a mold growth index reflecting the amount of mold mycelium on the surface of materials.

The index makes it possible to analyze the critical conditions needed for the start of growth, but it is also a tool to measure the progress of mold growth in different conditions and structures [16]. The mold index (M) is used as a pathology indicator.

Following Ojanen's classification of materials [18], we considered hemp and lime mix as very sensitive, mineral wool as moderate and existing wall as sensitive because of the aging of materials and the accumulation of dust that create a good substrate for mold. In the case of an interface, Ojanen recommends using the more sensitive of the two materials. Calculation of index $M$ starts six months after the beginning of the simulation, which corresponds to the end of the hemp and lime mix drying period once the water content has stabilized, furthermore, the alkaline environment ( $\mathrm{pH}$ about 12.5) generated by the lime inhibits the apparition of mold during the first months. Calculation runs up to the end of the third year. The maximum risk of pathology is considered as the maximum of mold growth during the three years tested $\left(M_{I} \max \right)$.

Viitanen et al. [26] suggested an assessment system according to the type of surface.

Table 2 : Failure criteria for mold growth risk assessment: traffic light classification [26]

\begin{tabular}{|l|c|c|c|}
\hline & Green (no risk) & Amber (possible risk) & $\begin{array}{l}\text { Red (unacceptable } \\
\text { risk) }\end{array}$ \\
\hline Mold index - surface & $\mathrm{M}<1$ & $1 \leq \mathrm{M} \leq 2$ & $\mathrm{M} \geq 2$ \\
\hline $\begin{array}{l}\text { Mold index - interfaces and } \\
\text { surfaces without direct contact } \\
\text { with indoor environment }\end{array}$ & $\mathrm{M}<2$ & $2 \leq \mathrm{M} \leq 3$ & $\mathrm{M} \geq 3$ \\
\hline
\end{tabular}

\subsection{Urban morphology indicators}

Three-dimensional urban morphology is mainly responsible for the modification of radiation fluxes and wind profiles. Furthermore, European medieval city centers present a specific urban organization. Here, we study the morphological characteristics by means of indicators in order to observe how the urban form modifies the outdoor boundary conditions. Various indicators are calculated thanks to ArcGIS and a coupling between ArcGIS and EnergyPlus at the scale of the exterior façade, each story of each façade being considered independently.

- The Aspect Ratio (AR) describes a perfect urban canyon defined as AR $=H / W$ with $H$ the height of the buildings and $\mathrm{W}$ the width of the street.

- The Sky View Factor (SVF) is defined as the fraction of the sky that is visible from a given point on a solid surface. Many of the studies related to radiation availability that have been carried out thus far have focused on the use of relatively simple geometric parameters (aspect ratio or Sky view Factor of the street) and how these relate to the degree of obstruction or degree of access to the sky view [27]. In our case, in order to obtain more 
precise indicators, we work with the SVF of each story of each façade instead of the SVF of the street, with a factor of 0.5 for a façade without any obstruction to its view of the sky. This indicator is calculated by EnergyPlus based on surface tilt and shadowing surfaces.

- Orientation of the façade from $0^{\circ}$ to $360^{\circ}$

- Number of stories per building, each story being considered as $2.7 \mathrm{~m}$ high

- Annual insolation (hours/year) represents the duration of direct radiation with clear sky, independently of local climatic conditions, and is calculated with EnergyPlus

- Annual global solar radiation $\left(\mathrm{kWh} / \mathrm{m}^{2}\right.$ per year) calculated with EnergyPlus

- Water quantity of driven rain reaching a façade per year, calculated with Delphin 5 depending on the wind exposure of the façade (orientation of the façade, speed and direction of the wind).

- Cumulative condensation potential: exterior surface condensation will occur when the surface temperature drops below the dew point temperature, calculated as a function of temperature and relative humidity of the ambient air. By analogy with the concept established by [28] and then used by [29], we define $\mathrm{CP}=\mathrm{P}_{\mathrm{v}}\left(\mathrm{T}_{\text {air }}\right)-\mathrm{P}_{\mathrm{v} \text {,sat }}\left(\mathrm{T}_{\text {surf }}\right)$. Here, we use the annual cumulative hours with a positive condensation potential, $C P h=\sum \Delta t_{C P>0}$

\section{Results and discussion}

4.1. ArcGIS and EnergyPlus coupling for exterior boundary conditions

As previously presented, the morphology of the urban environment modifies the external boundary conditions of the thermal and hygrothermal models, hence the need to detail the geometry of adjacent buildings to obtain consistent results. The first step was to validate the coupling ArcGIS and EnergyPlus as a tool to obtain reliable exterior boundary conditions. The reliability was validated by comparison with solar radiation measurements obtained in-situ in the monitored buildings located in the city center of Cahors. Sun radiation was measured by a pyranometer installed vertically on a $2^{\text {nd }}$ floor west-facing façade of the monitored dwelling. Measurements were taken every $1 \mathrm{~min}$ and data were recorded every $10 \mathrm{~min}$, as the average of the previous measurements.

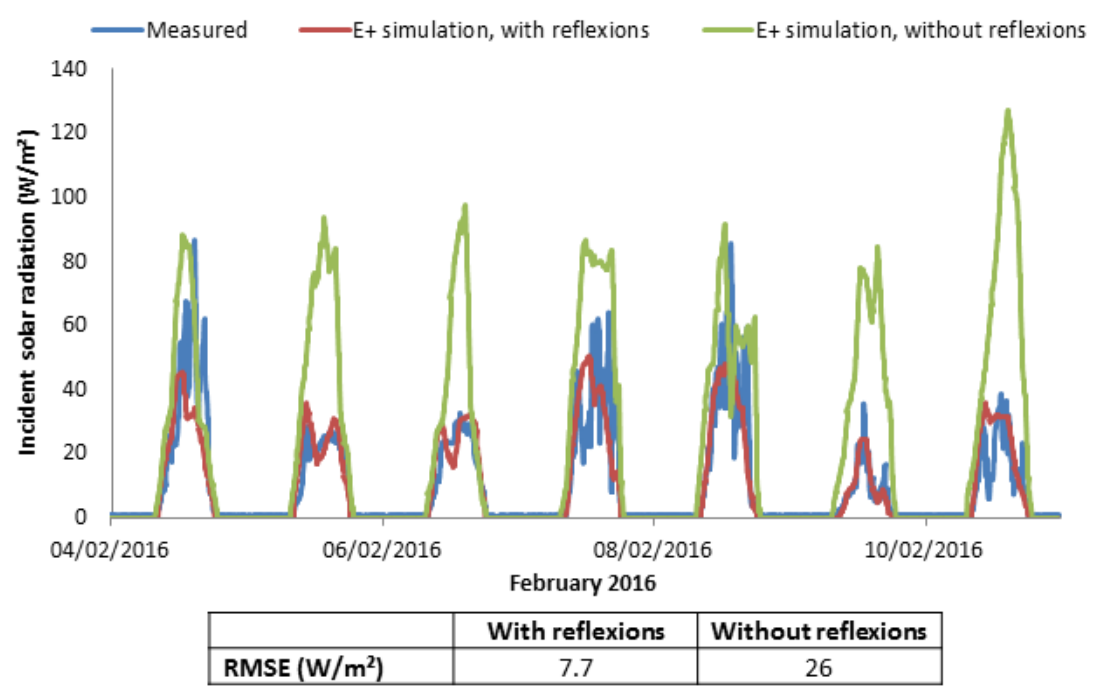

Figure 6: Comparison between solar radiation: measured and simulated with E+ 
Figure 6 compares the simulation results with EnergyPlus and the experimental data. For the same wall, two cases of simulations are analyzed: with and without reflections. EnergyPlus has an option to calculate beam and sky solar radiation that is reflected from exterior surfaces and then strikes the building under study. Surrounding building surfaces are assumed to be diffusely reflecting. For the ground surface, the shadowing is taken into account only if "with reflections" is used. Simulation with reflections shows a better correlation with experimental values. The "With reflections" option allows more precise consideration of the surrounding masks, for both the reflection of the direct and diffuse radiation on the surrounding ground and the interreflections between buildings. Our simulations were run with this option.

\subsection{Analysis of morphological indicators}

A Principal Component Analysis (PCA) helps to identify a possible correlation between the morphological indicators and to observe the distribution of indicators for each façade of the city center. The study points out that, when the orientation is taken into account, the SVF is a reliable indicator to describe the modifications of incident radiation on the façade.

Results have shown (Figure 7) that a significant alteration of the SVF value occurs in the city center. The sky view factor value is less than 0.05 for $57 \%$ of the ground floor façades and for $33.7 \%$ of all stories, which corresponds to a significant reduction of radiation.
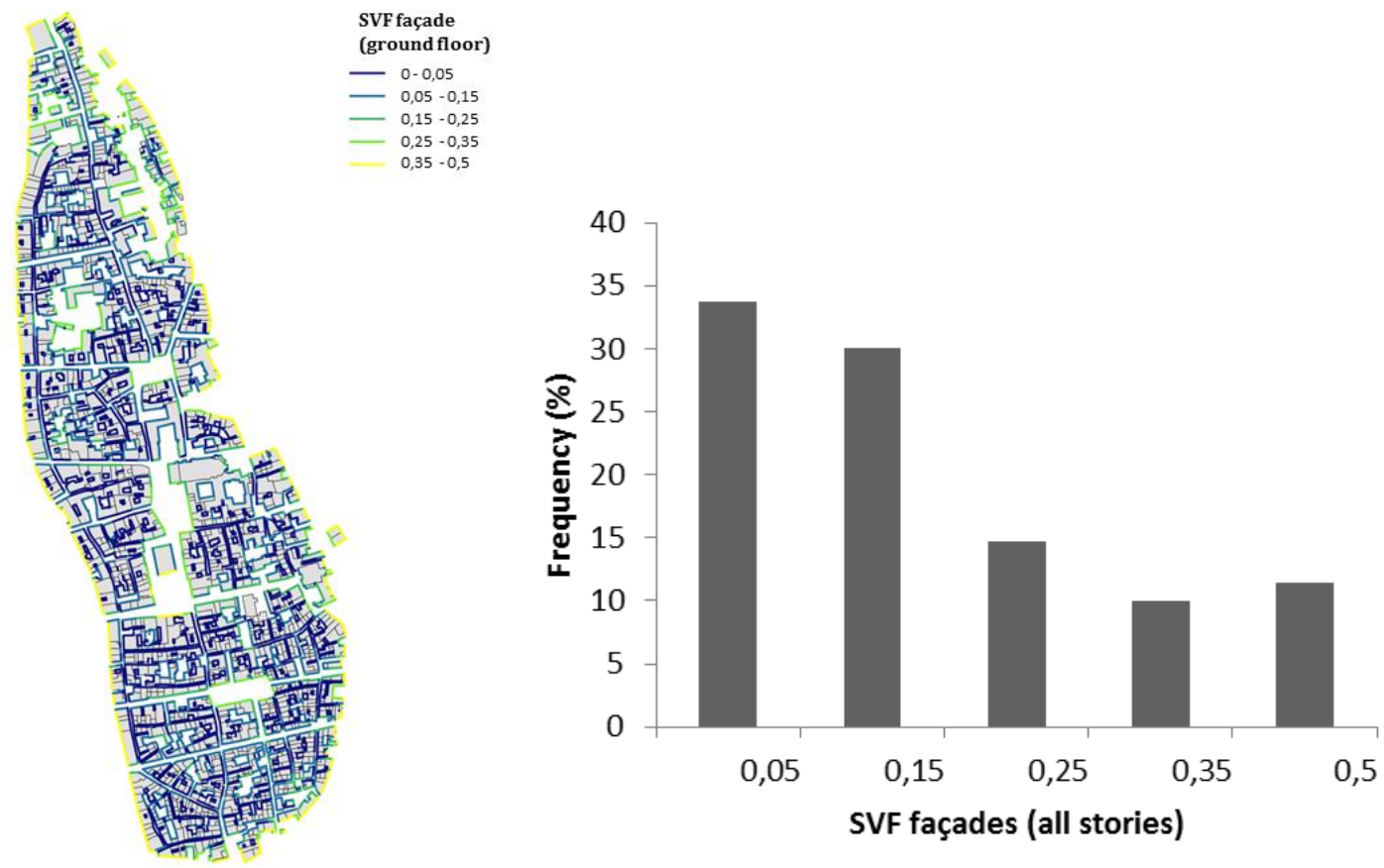

Figure 7: Mapping of the façade SVF of the ground floor (left) and frequency of façade SVF (right) for all stories of the city center

Figure 8 illustrates a correlation between façade SVF and Aspect Ratio (more common morphological indicator) to highlight how strongly the position of the façade (from the ground floor to $3^{\text {rd }}$ floor) modifies its SVF. 


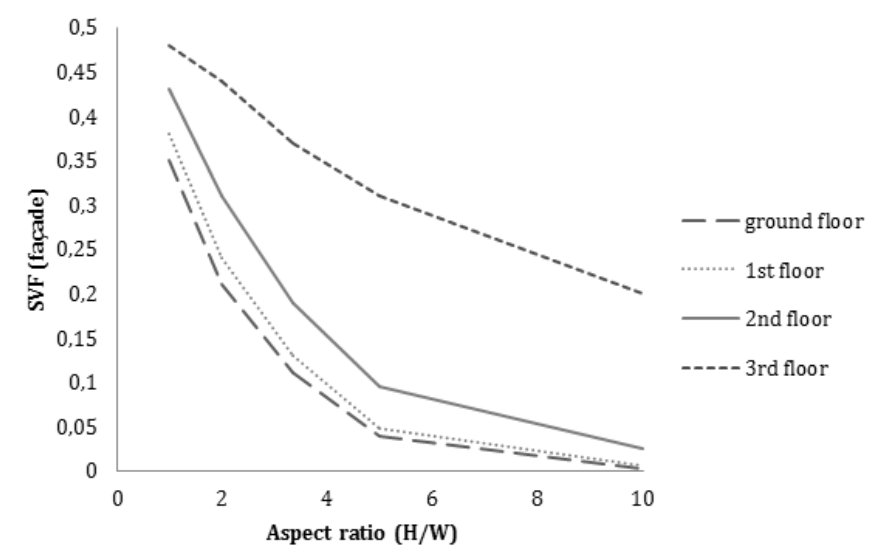

Figure 8: Correlation between AR and façade SVF for each floor

PCA also shows that the city center can be considered as a homogenous group of buildings in terms of urban morphology, no specific pattern being observed. It is thus relevant to reduce the study to a single representative urban block, once it has been verified that the distribution of morphological indicator values are similar between the chosen urban block the whole city center. For example, the representative city block has the same four main orientations as the whole city center (Figure 9). Studying a representative city block (44 buildings and 800 walls) instead of the whole city center (1400 buildings and 30000 walls) permits computation time to be drastically reduced.
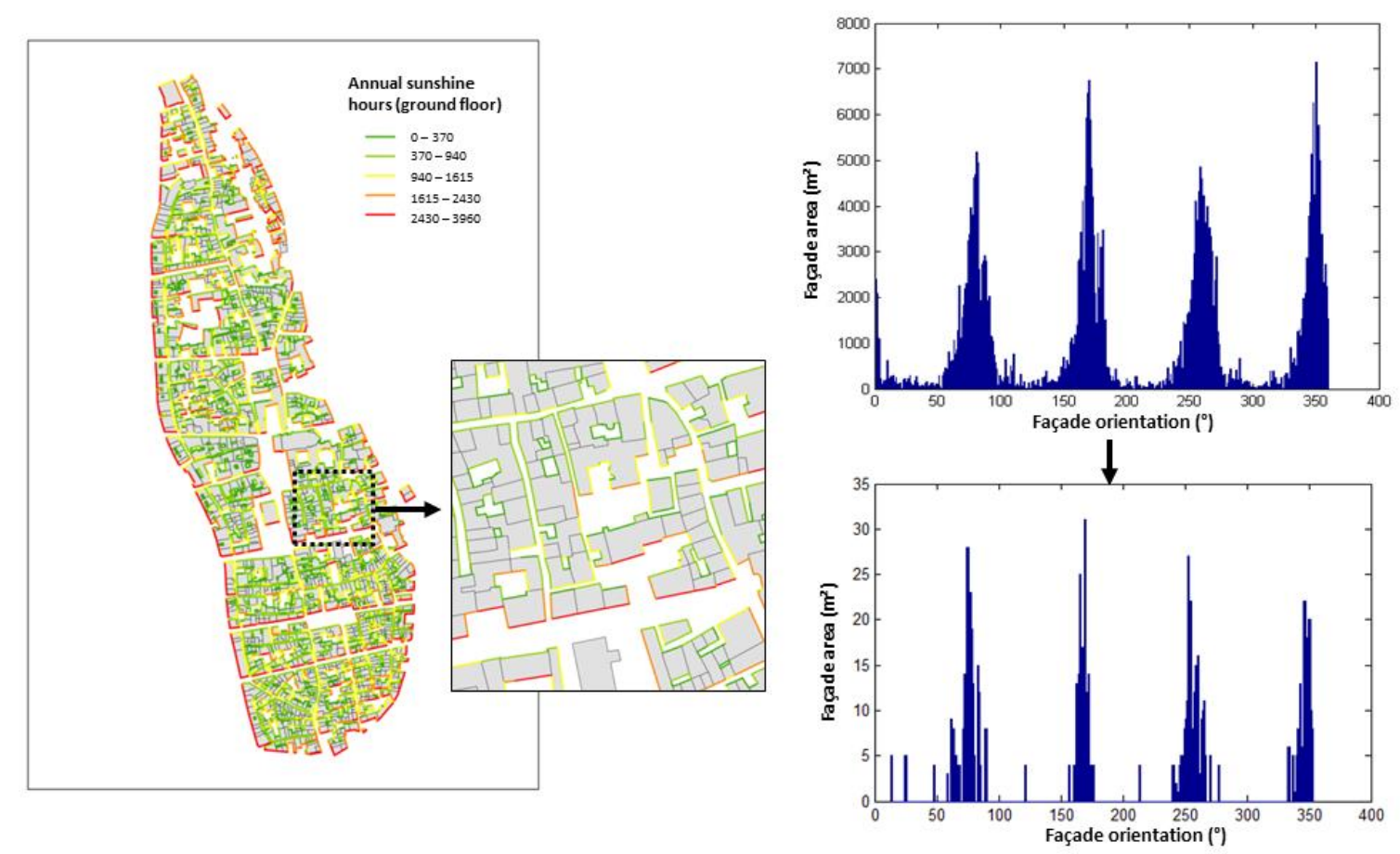

Figure 9 : Indicators of the city center and representative city block : annual insolation for ground floor façades (left), orientation of the façades (right)

\subsection{Assessment of risk of pathology}

Figure 10 presents the mold growth potential at the interface of a timber framed wall, located at different floors of a building in a very narrow street $(\mathrm{H}=12 \mathrm{~m}, \mathrm{~W}=2 \mathrm{~m})$. 


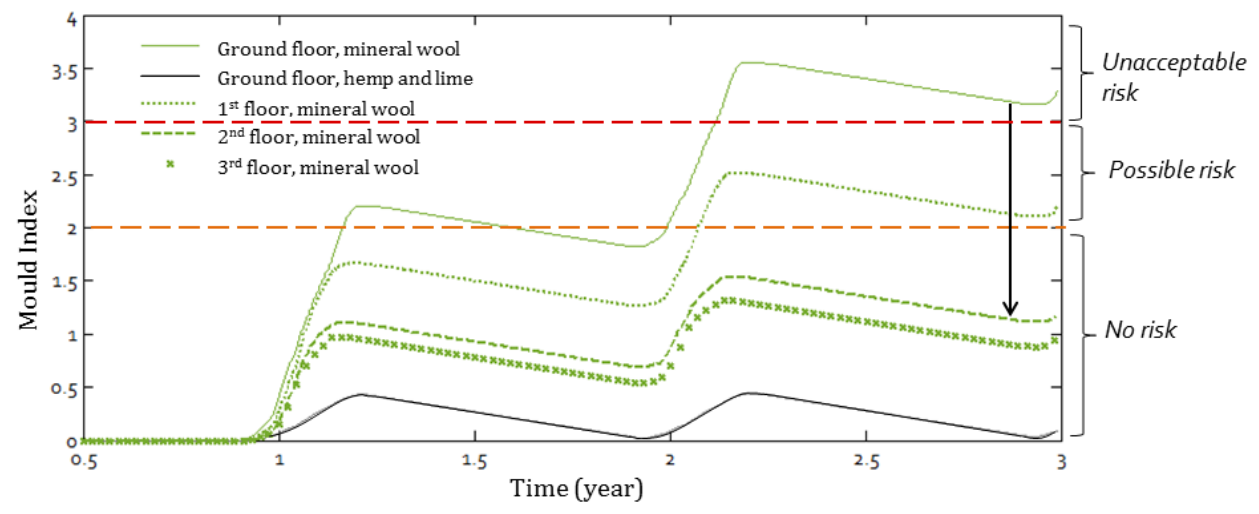

Figure 10: Mold growth potential at the interface of a timber framed wall

Different conclusions can be drawn from Figure 10. First of all, for the same wall located on the ground floor, a marked difference of mold growth is observed between the two insulation systems. The hemp and lime mix (HL) presents no risk of mold while the mineral wool insulation (MW) presents an unacceptable risk after 2 years. The second point is the difference observed for the same wall located at different floors: the different exterior boundary conditions lead to different mold growth, the ground and first floor presenting a risk while no risk is detected for the 2nd and 3rd floors.

The PCA establishes correlations between urban indicators and pathology risks. We observe that orientation has a major influence on the hygrothermal performance of a wall. For example, for a south-facing wall, the SVF appears to be a relevant indicator to evaluate the risk of pathology (Figure 11). For mineral wool insulation, façades with an SVF lower than 0.3 present a risk of pathology while, for hemp and lime mix, only façades with very low SVF present a possible risk.

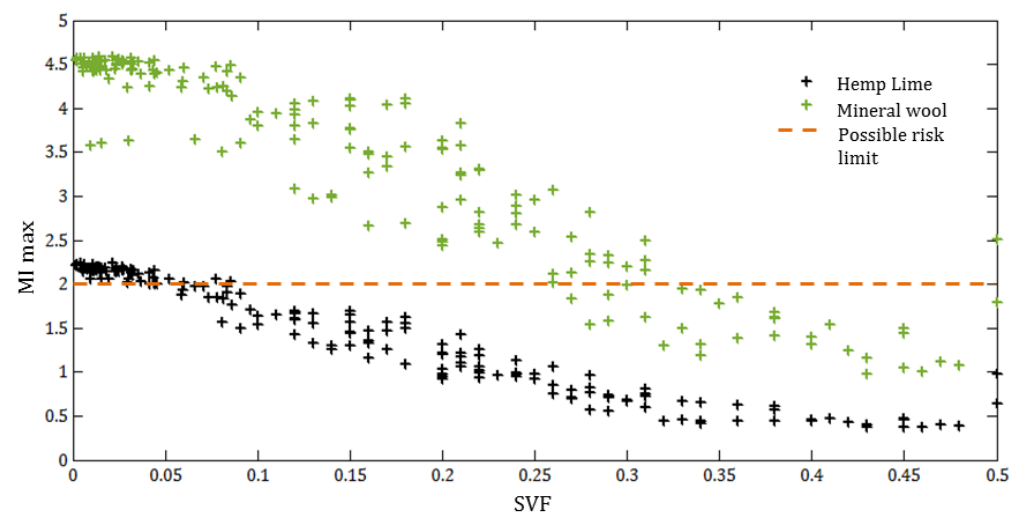

Figure 11 : Maximum risk of mold growth at the interface during three years of simulations for all south orientated walls of the representative city block (timber-frame typology)

For each orientation, PCA reveals a different major influence of indicators. Figure 12 illustrates the risk of pathology for each façade according to the orientation. 

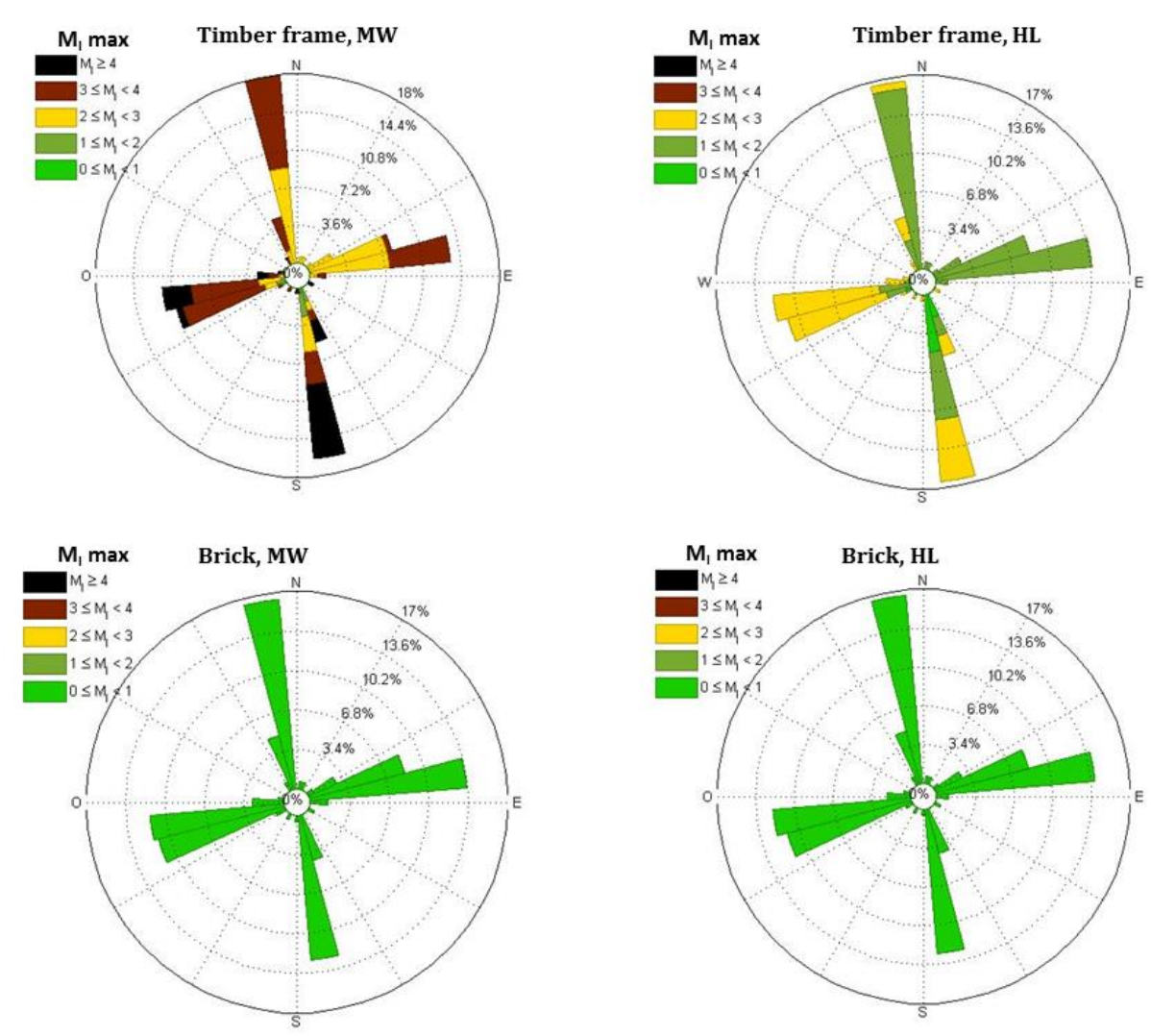

Figure 12 : Expression of the maximum mold index $M_{I}$ at the interface in cumulative surfaces

Risk is illustrated with the traffic light representation. This study highlights various observations:

- The timber framed walls are subject to a higher risk of pathology than massive brick walls, so they need to be insulated carefully. The small thickness of the timber framed wall is mainly responsible for this vulnerability.

- For both fabrics, mineral wool leads to higher relative humidity at the interface

- West-facing façades also present risks, but the appearance of a pathology is mainly due to Wind-Driven-Rain, which is more abundant for this orientation

- South-facing façades are particularly sensitive to the effects of masks on solar radiation. They will have the most different hygrothermal responses depending on the floor. The upper floors will be less sensitive, while the ground floor will be particularly vulnerable.

- The vulnerability of the North-facing façades mainly comes from the condensation potential. Unlike South-facing façades, top floors that face north can also be sensitive because of the greater radiation of the sky vault during the night. The use of brick on the façades reduces the risk of surface condensation thanks to its high absorptivity and thermal capacity, but North façades are not exposed to solar radiation and they cannot accumulate as much heat as other orientations. The North façades with a high Sky View Factor (upper floors or in streets with low aspect ratio) are exposed during the clear nights to radiation from the sky, that overcools the surface temperature and thus are more subject to surface condensation.

Finally, the pathology risk has been mapped for each façade of the city block using the GIS tool (Figure 13). The mapping provides a clear and highly visual deliverable for the city of Cahors with an urban planning tool. Again, the risk is mapped with traffic light representation. In Figure 
13, the higher risk of pathology with mineral wool appears clearly. For walls insulated with hemp and lime and presenting a risk, the addition of an efficient ventilation system is necessary to avoid high indoor relative humidity.
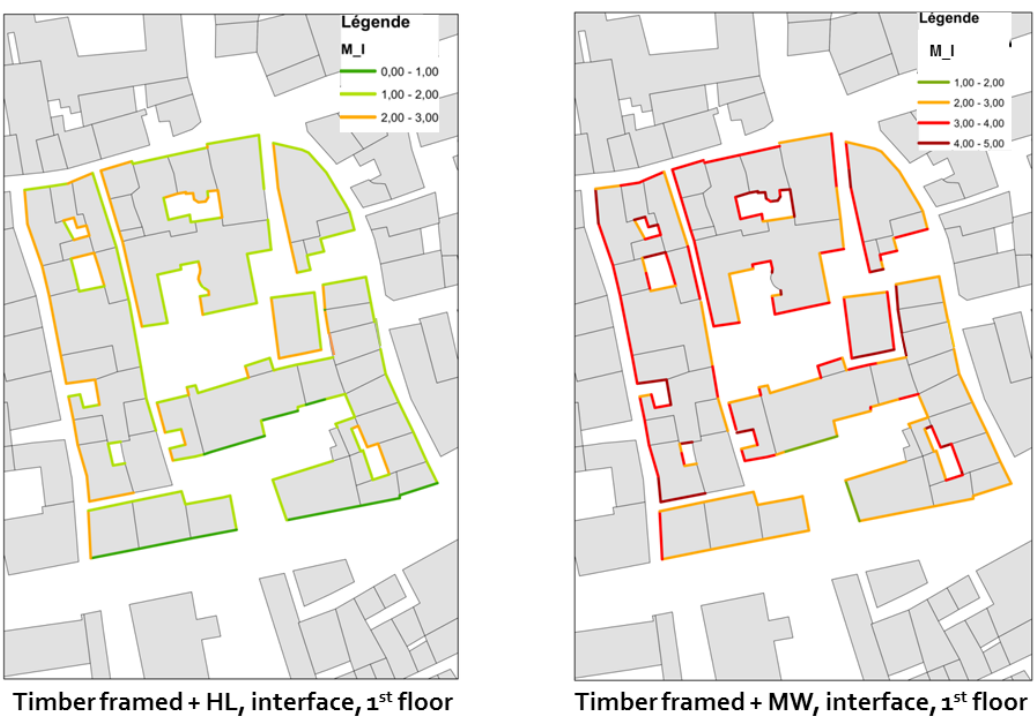

Figure 13 : Mapping of risks of pathology, with ArcGIS

\section{Conclusion}

This paper has presented a study conducted to estimate the long-term moisture response of façades, taking the urban morphology into account. The study highlights the fact that a building in a very dense area should not be treated in the same way as a stand-alone building, especially in terms of thermal radiation. Urban geometry must be precisely described to obtain relevant boundary conditions. Orientation has an effect on mold growth, mainly because of the variation in exposure to solar radiation and driven rain. The study points out that wooden framed walls should be refurbished carefully and that insulation with mineral wool presents a risk of decay due to the appearance of mold at the interface. The risk of decay is clearly decreased with the use of hemp and lime insulation. Furthermore, simulating walls with boundary conditions but without considering local microclimates can lead to insulation materials such as bio-sourced insulations being disregarded, while these materials present interesting features for a low carbon refurbishment of historical buildings. In the case of walls receiving extremely low solar radiation, risks are present even with hemp and lime insulation, and the recommendation will be to install an efficient ventilation system to avoid high indoor relative humidity.

Coupling software presents a relevant way to estimate boundary conditions while taking account of urban morphology. The use of a GIS tool since the beginning of the coupling allows the results to be mapped and an appropriate deliverable to be obtained for policy makers and urban planners. Mapping the results helps to identify areas where specific actions and recommendations are needed according to the risk of mold growth.

\section{Acknowledgements}

This research is part of the European project, ENERPAT (SUDOE), an EU Interreg funded partnership.

\section{References}


[1] S. Tasca-Guernouti, J. Bertron, J. Berger, L. Bourru, and F. Janvier, "Modélisation du comportement thermique du bâtiment ancien avant 1948, Tache 2: Rapport final," 2011.

[2] E. Stephan, "Méthode d'aide à la décision multicritère des stratégies de réhabilitation des bâtiments anciens en pierre calcaire : application au patrimoine en tuffeau.," École Nationale des Travaux Publics de l'État [ENTPE], 2014.

[3] S. Claude, S. Ginestet, M. Bonhomme, N. Moulène, and G. Escadeillas, "The Living Lab methodology for complex environments : Insights from the thermal refurbishment of a historical district in the city of Cahors , France," Energy Res. Soc. Sci., vol. 32, pp. 121-130, 2017.

[4] Y. Ko, "Urban Form and Residential Energy Use: A Review of Design Principles and Research Findings," J. Plan. Lit., vol. 28, no. 4, pp. 327-351, 2013.

[5] A. Matzarakis and H. Mayer, "Dependence of urban climate on urban morphology," in 5th Japanese-German Meeting on Urban Climatology, pp. 277-282, 2009.

[6] L. Adolphe, "A simplified model of urban morphology: Application to an analysis of the environmental performance of cities," Environ. Plan. B Plan. Des., vol. 28, no. 2, pp. 183200, 2001.

[7] S. Salat, “City and Forms, On Sustainable Urbanism.” Hermann, 2011.

[8] T. R. Oke, Boundary Layer Climates, 2nd ed., vol. 27, no. 3. 1987.

[9] V. Dorer et al., "Modelling the urban microclimate and its impact on the energy demand of buildings and building clusters," in 13th Conference of International Building Performance Simulation Association, Chambéry, France, August 26-28, pp. 3483-3489, 2013.

[10] J. Straube and C. Schumacher, "Interior insulation retrofits of load-bearing masonry walls in cold climates," J. Green Build., vol. 2, pp. 42-50, 2007.

[11] E. Vereecken and S. Roels, "A comparison of the hygric performance of interior insulation systems: A hot box-cold box experiment," Energy Build., vol. 80, pp. 37-44, 2014.

[12] A. M. Papadopoulos, "State of the art in thermal insulation materials and aims for future developments," Energy Build., vol. 37, pp. 77-86, 2005.

[13] S. Schiavoni, F. D'Alessandro, F. Bianchi, and F. Asdrubali, "Insulation materials for the building sector: A review and comparative analysis," Renew. Sustain. Energy Rev., vol. 62, pp. 988-1011, 2016.

[14] F. Pittau, F. Krause, G. Lumia, and G. Habert, "Fast-growing bio-based materials as an opportunity for storing carbon in exterior walls," Build. Environ., vol. 129, no. December 2017, pp. 117-129, 2018.

[15] M. Lawrence, A. Shea, P. Walker, and P. De Wilde, "Hygrothermal performance of biobased insulation materials," Proc. ICE - Constr. Mater., vol. 166, no. 4, pp. 257-263, 2013.

[16] H. Viitanen et al., "Moisture and Bio-deterioration Risk of Building Materials and Structures," J. Build. Phys., vol. 33, no. 3, pp. 201-224, 2010.

[17] K. Sedlbauer, "Prediction of mould fungus formation on the surface of and inside building components .," Thesis, University of Stuttgart, Fraunforer Institute for Buildings Physics, 2001.

[18] T. Ojanen, H. Viitanen, R. Peuhkuri, K. Lähdesmäki, J. Vinha, and K. Salminen, "Mold 
Growth Modeling of Building Structures Using Sensitivity Classes of Materials," Therm. Perform. Exter. Envel. Build. XI, pp. 1-10, 2010.

[19] M. Palumbo Fernández, "Contribution to the development of new bio-based thermal insulation materials made from vegetal pith and natural binders : hygrothermal performance, fire reaction and mould growth resistance," Thesis, Universitat Politècnica de Catalunya, 2015.

[20] K. Sterflinger, J. Ettenauer, and G. Piñar, "Bio-susceptibility of materials and thermal insulation systems used for historical buildings," Energy Procedia, vol. 40, pp. 499-506, 2013.

[21] K. Sedlbauer, W. Hofbauer, N. Krueger, F. Mayer, and K. Breuer, "Material Specific Isopleth-systems as Valuable Tools for the Assessment of the Durability of Building Materials Against Mould Infestation - The ' Isopleth-traffic Light,'” in XIIth International Conference on Durability of Building Materials and Components, 2011.

[22] C.-E. Hagentoft, Introduction to Building Physics. Lund: Studentlitteratur, 2001.

[23] M. Abuku, B. Blocken, K. Nore, J. V. Thue, J. Carmeliet, and S. Roels, "On the validity of numerical wind-driven rain simulation on a rectangular low-rise building under various oblique winds," Build. Environ., vol. 44, no. 3, pp. 621-632, 2009.

[24] A. Erkal, D. D'Ayala, and L. Sequeira, "Assessment of wind-driven rain impact, related surface erosion and surface strength reduction of historic building materials," Build. Environ., vol. 57, pp. 336-348, 2012.

[25] E. Vereecken and S. Roels, "Review of mould prediction models and their influence on mould risk evaluation,” Build. Environ., vol. 51, pp. 296-310, 2012.

[26] H. Viitanen, M. Krus, T. Ojanen, V. Eitner, and D. Zirkelbach, "Mold risk classification based on comparative evaluation of two established growth models," Energy Procedia, vol. 78, pp. 1425-1430, 2015.

[27] D. Robinson, "Urban morphology and indicators of radiation availability," Sol. Energy, vol. 80, no. 12, pp. 1643-1648, 2006.

[28] R. Zheng, "Performance of highly insulated zinc roofs in moderate humid regions," Thesis, KU Leuven, 2004.

[29] E. Barreira and V. P. de Freitas, "Experimental study of the hygrothermal behaviour of External Thermal Insulation Composite Systems (ETICS)," Build. Environ., vol. 63, pp. 3139, 2013. 